\title{
Biography: Hector Rolando Herrera Cabral—“Relearn What Has Already Been Learned"
}

\author{
Hector Rolando Herrera Cabral ${ }^{1,2}$
}

Received: 10 August 2020 / Accepted: 10 August 2020 / Published online: 24 August 2020

(C) Springer Science+Business Media, LLC, part of Springer Nature 2020

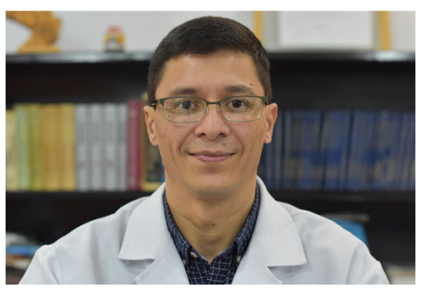

Hector Rolando Herrera Cabral, 48 years old, graduated from the Northeast University (UNNE) (Corrientes, Argentina) and is a former resident, chief of residents, and surgery service staff member of the Itauguá National Hospital. He is a surgery service staff member of the IPS Ingavi Hospital. He was a fellow in bariatric surgery at the Country Clinic, Bogotá, Colombia, and a member and former president of the Paraguayan Society of Bariatric and Metabolic Surgery. He is an active member of the IFSO.

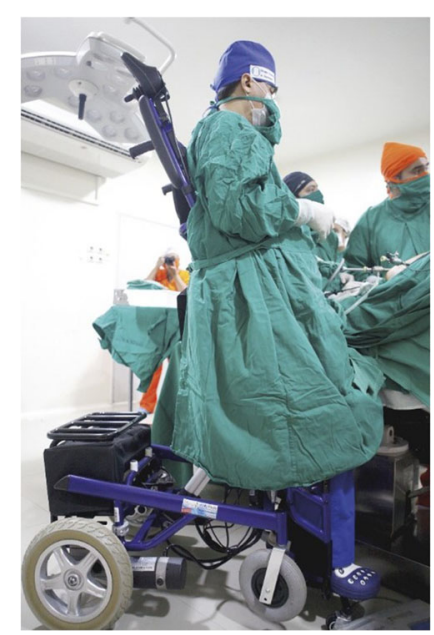

Hector Rolando Herrera Cabral

rolandpy@gmail.com; http://www.cirugiacontralaobesidad.com.py

1 IPS Ingavi Hospital, Fernando de la Mora, Paraguay

2 Country Clinic, Bogotá, Colombia

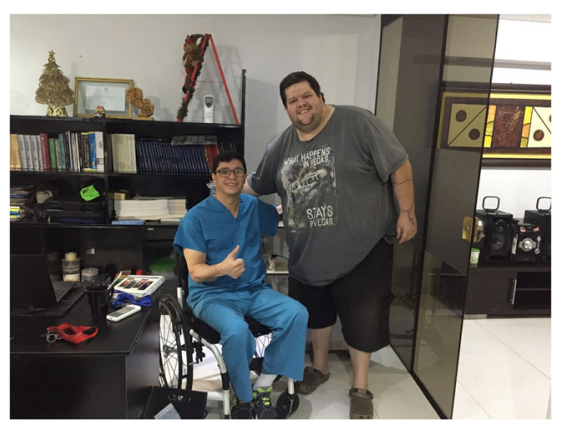

A year and a half ago, I suffered an accident when I was hit by a car while crossing the street. Unfortunately, it resulted in a spinal cord injury at the level of T4 which made it impossible for me to walk and left me dependent on a wheelchair. I am a doctor, surgeon, and specialist in laparoscopic surgery and bariatric surgery. This specialization has always been a passion of mine. After my rehabilitation, I decided that I would work to be as independent as possible. However, I was concerned that this goal might be quite difficult, even unrealistic.

Very close colleagues of mine were curious as to how I planned to continue working as a surgeon. I expressed my desire to them to that I truly wanted to continue performing surgery. They found a store where motorized wheelchairs are sold and that had a wheelchair that could lift a patient into an upright position. Strapped securely into this motorized wheelchair, I would be able to be safely in a vertical position.

This was a dream come true. Despite my injury, I could continue to do what I loved, being an operating surgeon. I would like to take this opportunity to thank my group of colleagues and friends, again.

We started off only doing simple, short surgeries, until we advanced to doing more complex surgeries. Over time, we realized that there were some details that we needed to change so that it would be more comfortable for me standing upright in the motorized wheelchair, so I could work for longer periods of time. For example, having my chest tied with a certain amount of tension allowed more mobility to my trunk and additionally, moving the chair 
forward or backward as required by the surgical moment. I thank the Lord that my hands and brain are intact, which after all are truly the "instruments" that do everything in an operating room. They make the exact movements that enable me to work on the organs and suture precisely.

The process for me to do an operation is as follows: First, the wheelchair must be in a standing position. Second, I scrub my hands, put on the sterile gloves, enter the operating room, and dress in the surgical gown. After that, we proceed with the laparoscopic surgery. Ultimately, we can pay close attention and concentrate in our work. Like all surgeons, we strive to do our best with each and every patient who places their trust in me and our team.

I started performing surgery again on March 2019. We had to develop unique techniques that would allow me to perform a variety of laparoscopic surgeries such as cholecystectomies, hernioplasties, Heller's esophagocardiomiotomy, hiatal hernia, choledocotomies, left adrenalectomy, and right nephrectomy. From July 2019 to July 2020, we also performed 14 bariatric surgeries: one sleeve gastrectomy, eleven gastric bypasses, one gastric bypass revision, and one conversion of a sleeve to a gastric bypass.
One of the main reasons that I was able to work again as surgeon is the motorized wheelchair that helps me be in an upright position. Nonetheless, there are other reasons as well, for instance, having the patience to create and learn techniques that allow me to operate in a wheelchair and, above all else, the belief that nothing is impossible and anything can be done if you are willing to work at it. If things do not work out well doing it in one way, then you must try to do it in another way and keep trying until you succeed.

Being in a wheelchair while performing a surgery might be challenging. However, having tenacity to continue striving, spiritual strength that constantly helps us from the time we wake up until the time we go to sleep, and with the help of a motorized wheelchair, I learned that I CAN DO IT!

Finally, we must never forget that one always has the opportunity to Relearn What Has Already Been Learned.

Publisher's Note Springer Nature remains neutral with regard to jurisdictional claims in published maps and institutional affiliations. 